\title{
Crowdsourcing as a method of transdisciplinary research - Tapping the full potential of participants
}

Originally published as:

Dietmar Wechsler (2014):

Crowdsourcing as a method of transdisciplinary research -Tapping the full potential of participants. In: Futures 60, 14-22 
Dietmar Wechsler *

Crowdsourcing as a method of transdisciplinary research Tapping the full potential of participants

* Corresponding author: Dietmar Wechsler, Wuppertal Institute, Döppersberg 19, 42103 Wuppertal, Germany

E-mail: dietmar.wechsler@wupperinst.org

Phone: +49 202 2492-178

Fax: +49 202 2492-138 


\title{
Crowdsourcing as a method of transdisciplinary research - Tapping the full potential of participants
}

\author{
D. Wechsler
}

\begin{abstract}
Within the scope of citizen science projects, crowdsourcing has already expanded into scientific application areas. In this, its scientific potential is only partly exhausted, however.

It will be shown that transdisciplinary research is made up in content and structural aspects in such a way that crowdsourcing can fully unfold as a research method through varied participation possibilities, reflective processes and use of contemporary technical possibilities. Furthermore, mutual learning, understanding and the dissemination of knowledge strongly profits from effects that even result automatically in this context.

The scientific application of crowdsourcing represented here makes high demands on project management, but it is expected to turn out as an effective research method precisely in the area of transdisciplinary research.
\end{abstract}

\section{Keywords:}

transdisciplinary research, crowdsourcing, citizen science, participation, web-based technologies, wisdom of crowds.

\section{Introduction}

Numerous uses are subsumed meanwhile under the concept of crowdsourcing characterised by Howe [1], meaning the assignment of certain tasks and problem formulations to a larger volume of people that is mostly not closely defined. In general this is realised by the use of modern web-based technologies.

In this, the participants make available certain resources and abilities (time, knowledge, computing capacity, data, pattern recognition, etc.), work together on the development of free solutions and offers (open source and open information activities like Linux, openstreetmap, wikipedia, etc.) or take part in open innovation activities (innovation and idea competitions, product tests and developments).

Their feasibility and conveyance via internet-based technologies and offers has contributed to the popularity and successful implementation of many crowdsourcing activities [2,3]. The technological possibilities of smartphones in combination with special apps do their part to expand the potential of crowdsourcing, as well as to shape it in a more mobile and more adaptable manner.

In the literature, as well as on the Internet, overviews and typologies can be found on the numerous activities which further illustrate the variety of application areas and application possibilities [4-8].

Though crowdsourcing could not establish itself yet as a common research method of (first) choice in the area of science, it can, however, already show respectable scientific achievements in the form of citizen science projects, in which by definition also non-scientists get involved in the research projects $[3,4]$. The question is still posed here how the scientific significance and use of crowdsourcing and the associated, much-touted "wisdom of crowds" 
[9] can be determined in more detail and where its use results in the biggest scientific added value.

Answers to this complex set of questions can possibly be found, in particular, in the area of transdisciplinary research. It essentially defines itself through the exploration of life-world problems with aspects of crossing and integration of disciplinary paradigms [10,11]. It therefore might provide, according to its comprehensive and community-oriented approach, good reference points for the scientific integration of crowdsourcing. What relations can be identified in this, and how crowdsourcing can be used as a method of transdisciplinary research, is something that is meant to be examined in this article.

The next chapter prepares this analysis by initially putting the three areas crowdsourcing, citizen science and transdisciplinary research in relation to each other. Starting with the fundamental scientific features of these areas, existing points of contact, differences and common characteristics are identified. In Table 1 the similarities and differences between the three fields are summarised.

Following that it will be analysed to what extent crowdsourcing can be used as a transdisciplinary method and what added values for transdisciplinary research thereby result. A concluding view sheds light on further scientific potentials, as well as on methodical improvements and testing of crowdsourcing that are still necessary.

\section{Crowdsourcing, citizen science and transdisciplinary research}

In numerous citizen science projects, volunteers gather scientific data, but also execute research, above all in the areas of organismal and environmental monitoring (butterfly monitoring, weather observation, investigation of the water quality etc., cf. [4]). Also other science areas, like astronomy and biochemistry, profit from the commitment of the community [3], e.g. the Foldit project conceived as an on-line game, in which the users design protein folding structures with respect to an optimum chemical stability.

Citizen science is found in different stages of scientific research [12]. Readiness to learn and tasks like image analysis and pattern recognition are being demanded from the participants in this context. Mostly the participation is limited, however, to the gathering of scientific data, while the evaluation, scientific classification, conclusions and publication are carried out by the scientists who have initiated the project.

This brief characterisation of citizen science implies that it is to be understood as a scientifically oriented form of crowdsourcing. Crowdsourcing itself encompasses many other aspects, like social and economic activities, that are not associated, or only to a low extent, with research projects and research objectives: offers oriented to knowledge and to information (e.g. Yahoo! answers, wikipedia, metadatagames), open collections of images, videos, music, texts, etc., assessments and decisions through questioning the crowd, industrial and/or social innovation projects and competitions, etc. (cf. [7]).

However, there are also crowdsourcing activities that, in spite of addressing a broad target group, are orientated primarily, on experts and scientists. Thus many Internet platforms within the scope of ideas and innovation competitions often address precisely those participants that have expert knowledge and special abilities, in order to solve industrial development problems, but also academically significant questions. This cannot be declared as citizen science since the tasks assigned to the participant group ("community") require expert knowledge and are, therefore, mostly not to be tackled by interested laymen. 
The same applies to many open source projects (e.g. wordpress, a content management system, or openfoam, a software package for computational fluid dynamics), provided that here, for example, special programming skills or other scientific expertise, is indispensable. However, one also finds in the specialist literature the position that open source activities (above all on account of their open organisations, decision-making and distribution structures) may not anyway be categorised under the concept crowdsourcing [13]. However, this standpoint is not being represented here since it imposes upon crowdsourcing artificial restrictions instead of enriching its spectrum of assignable tasks with the open source philosophy.

Open source and other crowdsourcing activities also display structural differences to citizen science projects. With the latter, it is distinguished clearly between volunteers and coordinating scientists. Therefore they have a hierarchical and, concerning the compiled and analysed scientific contents, closed structure [12]. Many other crowdsourcing initiatives have flat decision-making structures, are organised bottom up and are released at many levels for open editing and discussion. Besides, according to [14] the contributions of the community are often accessible immediately and can be attributed directly to individual participants, while, in the field of citizen science, small single contributions are rather not explicitly shown and a longer time span passes for results and publication.

So it must be noted that a citizen science project, while it can be classified as a crowdsourcing activity, however, only makes use of parts of the access methods of this area.

\section{Table 1}

In the next step, the relation is now discussed between citizen science and transdisciplinary research. For both science areas, non-scientific contexts play a major role: while the orientation to life-worldly issues is considered as a central transdisciplinary research object, non-scientific players are involved in research work in the field of citizen science. Although in many cases this goes hand in hand with the treatment of life-worldly issues, areas that stem primarily from the science field are also being worked on (see e.g. galaxyzoo.org, fold.it, wormwatchlab.org).

What role does the participation of non-scientific players play now for transdisciplinary research? Firstly, it remains to be noted that it is part of the transdisciplinary research philosophy to integrate practice partners, like interested citizens, affected persons, interest groups, authorities, companies, etc., that are connected with the field of research to be worked on (e.g. from areas like urban planning, environmental protection or resource efficiency). This serves above all to consider different life-worldly perspectives and interests, e.g. for the common definition of the research objective, to use local knowledge for the accurate detection of problems and, finally, to verify the practice suitability of the results of the research [15].

However, this kind of integration differs from citizen science since the players, as a rule, are not used for scientific work, but rather are considered as a benchmark, discourse partner, partly even as a research object themselves and as an addressee and/or multiplier for the dissemination of the project results.

The central science principle of transdisciplinary research consists of the integration of individual research areas, cooperation areas and fields of knowledge. It comprises interdisciplinary research [10] in its application to life-worldly problem fields. In the foreground of this is the development of systems knowledge (determination of the initial position and handling of existing uncertainties), target knowledge (weighting and clarification of the variety in objectives under the guideline of a problem solution approach oriented to the 
common good) and transformation knowledge (change possibilities with inclusion of existing technical, social, legal, cultural etc. framework conditions) [15].

Though transdisciplinary research is hence at home in the science landscape in a comprehensive, diverse and flexible manner, it does, however, have strong scientific guidelines and requirements like system integration, formative innovation principles, participation, recursive processes and validation $[10,16]$.

However, citizen science on the other hand defines itself simply methodically via the participation of volunteers in the scientific work and is otherwise free in scientific framing and target definition. Thus it is for example also possible that a citizen science project is only initiated and is coordinated by representatives of one research discipline, who then also handle the evaluation and analysis of the data gathered by non-scientific participants. In contrast transdisciplinary research always has the claim of operating in a transdiscipline manner and of integrating disciplinal knowledge resources, methods and procedures for the purposes of the task definition.

In spite of the identified conceptual differences between citizen science and transdisciplinary research, points of contact and areas of overlap absolutely exist between the two fields. Starting from a life-worldly problem formulation and a transdisciplinary alignment of the responsible scientists, quite a lot of citizen science projects, in particular from the area of environmental research, can even be reworded as transdisciplinary research projects, where the tackling of scientific tasks by the crowd is understood as a research method.

If, however, one now wants to exploit the full potential of crowdsourcing for transdisciplinary research, one must go beyond the relation shown in the area of citizen science that, after all, covers crowdsourcing only in subareas (see above). The use of the latter as a transdisciplinary method must hence subsequently be identified in more detail first, namely in comparison to the scientific requirements and guidelines of transdisciplinary research (cf. Section 3).

\section{Analysis and impact of crowdsourcing as a transdisciplinary method}

Participation is considered a central factor for the execution of transdisciplinary activities and is naturally the core module of crowdsourcing. Forms, possibilities and the extent of participation therefore form the analytic foundation in order to define the methodical content of crowdsourcing for transdisciplinary research.

The following survey of the discussion about the participation of stakeholders in transdisciplinary research projects is meant to prepare the way for new perspectives of participation offered by crowdsourcing, which will be discussed in the subsequent sections.

\subsection{A small literature review on participation frameworks}

According to Elzinga [17] participation theory for transdisciplinary projects is still in a quite underdeveloped state and in most cases participation only takes place in the first phase (problem identification and structuring) and in the last phase (implementation) of a research process. Elzinga emphasizes the meaning of reflection for performing and analysing participation processes. For this, the following aspects should be considered: is it an effective or rather symbolic participation, who is considered for participation and what relations, material and cultural resources might occur in this context? 
Mobjörk [18] discriminates between consulting and participatory transdisciplinary research. In the first case participants only act in a consultative way, whereas in the second case knowledge from the life-worldly regime is on equal footing with scientific knowledge for executing the project. This categorization might be a little bit misleading, because in both cases there is participation to a certain degree. Nevertheless this does not affect Mobjörk's conclusion, that the second case is "attractive, but much more demanding and timeconsuming than a consultative transdisciplinary approach."

Ulrich [19] also points out the importance of reflexivity in the context of participation (as Elzinga, see above). Within the framework of his concept "critically systemic thinking" each participant should reflect their own system boundaries (perception and evaluation boundaries). Ulrich distinguishes four so-called boundary issues: "sources of motivation, power, knowledge, legitimation." Each should correspond to a social role of a person involved: "client, decision-maker, professional, witness." In this context, he concludes that experts and citizens should meet as equals.

Enengel et al. [20] contribute to the discussion with a distinguished analytical framework, which splits into four denominations: "typology of actor roles", "research phases", "objectives and forms of actor integration", "types of knowledge". Within the first category they differentiate between the following roles: "core scientists" (e.g. scientific supervisor of the project), "scientific consultants" (e.g. external academic experts), "professional practice experts" (e.g. experts in practical and political aspects of the project), "strategic case actors" (e.g. local politicians or organisers of the project), "local case actors" (e.g. residents affected by the issue under consideration).

The framework is used to analyse four transdisciplinary doctoral projects. One result, which should be mentioned in the context of our analysis, corresponds to the observation of Elzinga (see above), namely "that participation appears to be more prominent in the initial and final phases of a research project."

Another framework has been realised as a "stakeholder participation guidance" (developed for the Netherlands Environmental Assessment Agency), which is organised along five central questions (cf. Hage et al. [21]): "why participation", "what should participation be about", "who to involve", "how much participation", "what forms and methods to look for".

Again reflexivity (and transparency) is pointed out as being very important for effective participation processes. Furthermore it is recommended to be aware of context dependencies (e.g. for choosing appropriate methods) and to use stakeholder participation especially in the case of "moderately structured and unstructured problems."

It is worthwhile to extend the literature review on participation frameworks beyond the direct view on transdisciplinary research, as there are many points of contact to it. Therefore the following reviews are recommended for further reading:

Reed [22] provides a literature review about stakeholder participation within the framework of environmental management. Different participation typologies are reflected, which respectively represent specific qualities: "degrees of participation", "nature of participation" (with respect to communication flows), "normative and/or pragmatic participation", "objectives for which participation is used." Furthermore, based on the literature analysis eight points for "best practice stakeholder participation" have been identified.

A complementary review with respect to stakeholder analysis methods can be found in [23]. Methods for "identifying stakeholders and their stakes", "differentiating between and categorising stakeholders" and "investigating stakeholder relationships" are reviewed. 
The last review to be mentioned here is about the field of participatory integrated assessment (Salter et al. [24]), which, for example, is applied in the context of climate change and related sustainability issues. Corresponding projects, as well as other publications, are reviewed and participation issues are arranged with respect to "mechanisms of participation, representation, and stages of involvement."

These three reviews (and references therein) altogether provide an extensive and structured overview about participation frameworks discussed in scientific literature. In general they can also be used for reflecting and framing participation processes in transdisciplinary research projects. Nevertheless, according to our understanding, the participation discussion should consider more and new aspects, as will be presented in the next section.

\subsection{Classification of transdisciplinary participation roles}

The literature reviewed above about participation frameworks does not consider crowdsourcing at all. This comes as a surprise, because the concept of crowdsourcing is already widely used in the scientific literature about citizen science (cf. Section 2).

Furthermore the variety of possible roles taken over by involved stakeholders is not considered as a central criterion for the realisation of participation processes (roles are discussed at least in $[19,20]$, cf. Section 3.1). Also the classical dividing rule between researchers and non-scientific stakeholders has still been maintained.

Therefore, in this section, more weight will be given to the discussion of possible participation roles within a transdisciplinary research process, the more so as crowdsourcing fosters the integration of a broad spectrum of roles and their flexible use.

While up to now essentially stakeholders from economy, politics and society, who have any kind of connection with the problem situation, have been integrated in a transdisciplinary manner, but who assume no active role in the execution of research projects, the catchment area is being strongly extended by crowdsourcing, both quantitatively as well as concerning the contents.

Participation possibilities exist for this in the following regard: as

(1) knowledge holders

(2) researchers

(3) involved citizens: concerned / responsible / competent participants

(4) interested citizens

(5) supporters

(6) examiners and evaluators

(1) Participation as a knowledge holder involves the integration of information (e.g. knowledge about local specific features, historical contexts, etc.) that is to be assigned according to its significance to the areas systems knowledge, target knowledge and transformation knowledge.

(2) Through the participation role as a researcher, the scientific work does not only remain within a narrower circle of scientists, who pursue a project full-time. Scientific contributions by people with special knowledge and abilities, or experts from certain specialist fields, who are integrated into the project, for example via respective internet platforms, can support the solution finding process or even solve the scientific challenge under consideration.

(3) In the next category (involved citizens), three participation options are summarised that, as a rule, have a direct project relation with different motives. Firstly there are concerned 
participants who are possibly affected by the research object (e.g. in the form of an illness, environmental destruction, aircraft noise, etc.) and of these, there are also some who are prepared to take part in studies. This contrasts with the category of responsible persons who cause a problem situation, for example by pursuing certain goals with undesirable side effects (e.g. environmentally polluting production processes). Finally, competent people like decision makers and representatives of organisations are also to be included who have a certain regulatory, mediating or supporting responsibility in a problem situation.

(4) Furthermore, participation via crowdsourcing is also an instrument with which the interested citizen can be addressed who can gradually familiarise himself with the topic via smaller contributions, comments and questions, which can then also become part of the knowledge development and reflexion within the scope of the transdisciplinary research process.

(5) In the role of supporter, a participant can involve himself by rendering services like preliminary research work (e.g. simple data collection), practical support (e.g. through the provision of computing power or material resources, taking on organisational duties), financial support, consultation services, dissemination of the results of the research, etc.

(6) Finally, the participant can accompany the research process as an examiner and evaluator on the basis of his respective knowledge and experiences. This is to be understood for the purposes of a crowd-based validation of certain work steps, outcomes and procedures of cooperation etc., as is already being carried out via Internet platforms in numerous contexts (discussions in appropriate forums, comment functions, on-line evaluation of contents, services and products, etc.). This utilisation of modern web-based technologies, as well as of tools from the areas of project management, knowledge management and innovation management, is vital for the purposeful execution of crowdsourcing that nowadays extensively makes use of these possibilities. The concept of crowdsourcing already implies meanwhile the use of these technologies, which are therefore also to be considered for the application as a transdisciplinary method and all of the named participation facets.

\subsection{Crowdsourcing within the transdisciplinary research process}

The section above illustrates how the community unfolds into different roles, which strengthen the principle of participation according to their great variety provided by "sourcing the crowd". The following discussion is devoted to the concurrence and integration of roles in the framework of crowdsourcing. It is structured along central research principles, adherence to which transdisciplinary research activities strive for. The results of this analysis are summarised in Table 2.

\subsubsection{Participation along all research phases}

On account of the variety in participation possibilities and a participant group that is diversified in its approach, crowdsourcing should be able to make contributions in all phases of research. According to $[17,20]$ this could not be realised up to now, as participation primarily takes place in the first and last phase of a research process (cf. Section 3.1). Based on crowdsourcing processes, the part in between, the scientific problem analysis, is also accessible to the community, e.g. by opening scientific tasks and subtasks for discussion and editing in the framework of a web-based cooperation platform. In this way the role of the researcher is extended to the community.

Furthermore the crowdsourcing approach offers the possibility that one person can take on more than one role during the research process. This flexibility provides new innovative and reflective aspects in all research phases, whereupon a dogmatic attribution of certain roles to specific research phases would not conform to the principle of crowdsourcing. 


\subsubsection{Integration}

Crowdsourcing first generates a variety in participants, cooperation options, knowledge stocks, innovation potential etc., but then also integrates the single contributions via reflective community activities, like assessment procedures, comparisons, exchange, communication and collaborative project work. Thus, common texts originate, e.g. from use of a Wiki, which can be compiled, read, changed and complemented by the community on-line and in the ideal case will converge into generally accepted contributions.

It is not only the integration of knowledge but also the integration of different roles and actors that can receive new impulses and development possibilities precisely by means of such crowdsourcing processes.

Moreover, transdisciplinary processes of integration also avail themselves methodically with the help of formal models (in particular by system modelling) [10,15]. The use of appropriate wiki and project management tools offers the possibility, within the scope of crowdsourcing, to collectively compile a jointly accepted model in which the knowledge assets and competencies, as well as the fields of interest from the community, will be reflected.

\subsubsection{Innovation}

According to [10], there are four innovation heuristics that relate to the identification of new scientific structures and solution approaches within the scope of transdisciplinary integration: the identification of lead structures and interfaces (often called "boundary objects" in the transdisciplinary context), transfer of methods and knowledge beyond disciplinary borders, the variation principle (performing of small change processes to discover new scientific ways) and the recursion principle (reflective and revision-oriented retrospective on research processes already running).

It is precisely a heterogeneous participant group with different roles and related knowledge and experience values that might produce unexpected lines of thought and hence new innovation impulses. Therefore all four innovation heuristics will be strengthened by considering a variety of community inputs.

For example, the variation principle and, for this, specifically the concept of controlled selforganisation [10], is predestined for a methodical application of crowdsourcing: controlled self-organisation means that targeted changes at specific points in the research procedure can trigger developments which open new points of view concerning the problem situation. As a rule, crowdsourcing implies (more or less controlled) self-organising community processes (forum discussions, new contacts and interactions, polls etc.) which also can open new research paths.

All roles described in Section 3.2 can contribute substantially to innovation processes.

Knowledge holders might induce new developments by providing (unexpected) information. Researchers are associated with innovation processes by nature and participants who adopt this role can contribute, e.g. by trying to solve tasks in the framework of web-based open innovation activities.

Involved as well as interested citizens offer new starting points for the generation of innovation according to their different backgrounds and motivations whereas supporters foster their realisation in the first place. Examiners and evaluators go along with innovation processes by reflecting those activities (this can also be understood in direct analogy to open innovation activities, e.g. appropriate to the integration of customer feedback in product development processes and tests).

$\underline{\text { Table } 2}$ 


\subsubsection{Recursion and Reflexivity}

The recursion principle, to which great importance is attached in the transdisciplinary discussion [16] (it also has been considered in [10] as an innovation heurististic), is further strengthened by the crowdsourcing processes: according to the significance of reflexivity, as pointed out in Section 3.1, the community reflects the research project and puts certain processes, results and participation roles in context with each other. Supported for example through web-based searching, comment and assessment functionalities, continuous illumination and verification of the processes can take place. Crowdsourcing thereby increases the likelihood of finding appropriate revision points and contexts concealed up to now.

\subsubsection{Validation}

Phases of the evaluation and quality assurance are, as a rule, a component of transdisciplinary research projects. Naturally those phases are covered by the role of an examinator and evaluator, which nevertheless is also used in the framework of innovative, recursive and reflective processes during the whole research work. In this way explicit validation phases can be also organised and enriched by crowdsourcing processes as already described above.

\subsubsection{Mutual learning, understanding and dissemination of knowledge}

The transdisciplinary research project, in particular the conveying and implementation of project results in practice, still profits from quite another effect that should result automatically by itself, or as a welcome side-effect when using crowdsourcing. Within the scope of the variety of participation roles, the community actively integrates itself in the research process. Depending on the current task and role, a participant will deal with certain contents, tasks, other fields of interest and viewpoints. In this, his own knowledge base also grows, contacts and mutual learning incentives originate, something that should, for example, trigger (unexpected) recursive and validation processes and, last but not least, also understanding and consensus processes. A participant with low interest at first can develop into a player with decisive contributions, and another person, who is affected by the problem situation, receives and compiles essential information and solution options for his case, as well as a certain understanding for comprehensive contexts, etc.

The participation via crowdsourcing therefore carries in its wake the life-worldly integration of the results of the research and the associated action recommendations. This happens first within the community, which then is also able to contribute to further dissemination and acceptance beyond the limits of the heterogeneous participant circle.

\subsubsection{Open management processes}

A successful inclusion of crowdsourcing into transdisciplinary research stands and falls with the quality of the project management. The composition of the community, role allocation, cooperation and communication, the coordination of individual crowdsourcing activities, the purposeful use of modern communication and project work means and, last but not least, the consideration of motivational situations and the creation of incentives, are important aspects for this that have to be considered.

The management of transdisciplinary research projects is anyway characterised by complexity and extensive coordination processes [16, p. 438]. It is a matter of taking into account the interests, obligations and working structures of the (leading) researchers with respect to their institutional and professional placement, and something else that has to be considered is the need to preserve the balance between interdisciplinary, cooperative research projects and purely disciplinal contributions. Crowdsourcing and the variety of roles seem to rather complicate this situation. 
On the other hand, crowdsourcing activities absolutely subsist on bottom-up processes that, after all, also contain regulative and recursive procedures. In this respect, it is a matter of questioning classical, hierarchical management structures and of opening them up, i.e. transferring decision-making, control, and design processes to the community and/or carrying them out in mutual cooperation. As important guidelines for this, the following should be resorted to: strong collegial understanding in relation to all participants (in accordance with [19], cf. Section 3.1), as well as comparative consulting, trying out and further development of organisational structures that have proved themselves in other crowdsourcing contexts.

Another important control and success factor lies in the motivation of the participants. Different incentives and motivational situations can influence the willingness to co-operate, the quality and quantity of the contributions. Extrinsic (status, networking, premiums, etc.) as well as intrinsic motives (playfulness, identification with the project, interest and pleasure, intellectual challenge, etc.) are to be considered, for this. Meanwhile, in the context of crowdsourcing, research projects devote themselves to the question of which motivation factors are the decisive ones for certain tasks [14, 25-27].

As another recommendation, it makes sense precisely in the interdisciplinary and transdisciplinary area to couple central management duties to discipline-covering competencies, so that the coordinating outlook and necessary creation of elbowroom are not warped by technical and institutional limits.

\section{Conclusion and outlook}

To sum up, it can be stated that crowdsourcing has high scientific potential for the treatment of research projects. Within the scope of citizen science, numerous scientific activities are already carried out by means of the integration of volunteers in the research project. In this, however, only a part of the possibilities of crowdsourcing is exploited. The analysis in the section above shows that, through the methodical use of crowdsourcing within the scope of transdisciplinary research, numerous participation roles for the generation of scientific results are possible that can be realised with the use of modern technologies, above all web-based technologies. Individual scientists, who (at first) do not belong to the scientific core team of a transdisciplinary project, are to be addressed in the area of the community just as much as initially non-scientific players, who - with their different abilities, knowledge, interests, experiences and motives - can contribute to the research project and its reflexion.

Especially the life-worldly orientation of transdisciplinary research offers ideal requirements to exhaust the scientific potential of crowdsourcing in many respects, as described above and summarised in Table 2.

One might ask who is in and who is out in crowdsourcing research processes. For crowdsourcing this is not a question of preselection before starting a research project. From the beginning, participation is usually open to everybody who wants to join the community. The further development of participation is a very flexible process, that might be ruled by the tasks and corresponding roles, certain access criteria, incentives etc. offered to the community. For example, the activity of a user or the quality of his contributions so far (which might be rated by the community), can be used as an access criterion for certain scientific tasks which should be performed only within a smaller circle.

As crowdsourcing in general means web participation, then personal contact, forms of cooperation, responsibilities, access, identification and security aspects are different from unmediated forms of participation, e.g. by working together in a lab. This might be seen as a drawback of this method. On the other hand crowdsourcing is not meant to replace 
conventional forms of cooperation in transdisciplinary research projects, but to extend the range and possibilities of participation.

The results of this analysis should prepare and motivate the systematic practical testing of crowdsourcing as a method of transdisciplinary research. For this, there are still open questions that need to be resolved, such as how to ensure the reliability of data that are collected by crowdsourcing. This, again, could happen for example with the help of community-based control, redundancy and recursive processes. There is also a need to explore the cooperation stages (individually compiled solution contributions up to the collective processing of tasks), allocation of duties, working forms and management measures that are appropriate to the particular problem.

Playful and competitive environments, general or specialised web platforms, design and maintenance of relevant communities, comparative orientation on successful open innovation and open source projects (cf. [28]), are additional factors that should be specified, tested and further developed in greater detail.

The fertile ground that crowdsourcing encounters in the area of transdisciplinary research should be used not only to determine and to optimise procedures, but also to investigate its fundamental scientific capability more closely. Something that is of interest here, for example, is the question on the basis of which factors the significance of group decisionmaking processes has to be defined [29], or to what extent certain scientific challenges (for instance a mathematical demonstration of proof) can be disassembled and be divided into simpler task packages.

It also gets interesting (for all roles described in Section 3.2) when active and passive crowdsourcing meet, which is a situation that is to be expected precisely in many a lifeworldly context of transdisciplinary research: a community member can contribute actively, for example by text contributions, to the solution of a task, but can also do so passively, for example by the fact that his behaviour patterns and movement patterns are analysed in specific situations (but this is nevertheless a sensitive topic, precisely because of the possibilities of modern technology, that must be handled responsibly and transparently). The participant who might be directly affected by the topic to be researched will therefore serve himself as the examination object in order to collect data that are used, for instance, for the investigation of the spreading of epidemics, behaviour forecasts etc. In the end, one can also analyse the research procedures under community participation oneself with the assistance of methods from system theory and social network analysis, in order to optimise these and/or to identify the factors for successful collaboration. A participant can find himself, in any case, in a double role, which leads to the fact that the observer and the observed can no longer be considered separately. Correlations and dynamics originating in this manner and relating to each other have to be reflected and monitored for the purposes of the task definition and/or used constructively as a (converging) feedback and self-organisation process for the problem solution.

The use of crowdsourcing as a method in transdisciplinary research therefore has the potential to provide new impulses in many respects - in the theory of science as well as in research practice. 


\section{References}

[1] J. Howe, The rise of crowdsourcing, Wired Magazine 14(6) (2006) 1-4.

[2] A. Doahn, R. Ramakrishnan, A.Y. Haley, Crowdsourcing systems on the world-wide web, Communications of the ACM 54(4) (2011) 86-96.

[3] E. Hand, Citizen science: People power, Nature 466 (2010) 685-687.

[4] J.L. Dickinson, B. Zuckerberg, D.N. Bonter, Citizen Science as an Ecological Research Tool: Challenges and Benefits, Annu. Rev. Evol. Syst. 41 (2010) 149-172.

[5] D. Dawson, Open science and crowd science: Selected sites and resources, Issues in Science and Technology Librarianship 69 Spring (2012). Available electronically from http://www.istl.org/12-spring/internet2.html (3.12.2013).

[6] S. Ekins, A.J. Williams, Reaching Out to Collaborators: Crowdsourcing for Pharmaceutical Research, Pharmaceutical Research 27 (2010) 393-395.

[7] http://en.wikipedia.org/wiki/List_of_crowdsourcing_projects (3.12.2013).

[8] E. Bonabeau, Decisions 2.0: The Power of Collective Intelligence, MIT Sloan Management Review 50(2) (2009) 45-52.

[9] J. Surowiecki, The Wisdom of Crowds, Anchor Books, New York, 2005.

[10] D. Wechsler and A.C. Hurst, Interdisciplinary system integration and inducement of innovation: a methodological approach for interdisciplinary research, Journal for general philosophy of science 42, 2011, 141-155.

[11] C. Pohl, What is progress in transdisciplinary research?, Futures 43 (2011) 618-626.

[12] A. Wiggins, K. Crowston, From Conservation to Crowdsourcing: A Typology of Citizen Science, Proceedings HICSS 44 (2011) 1-10.

[13] D.C. Brabham, Crowdsourcing as a Model for Problem Solving, Convergence 14 (2008) 75-90.

[14] O. Nov, O. Arazy, D. Anderson, Technology-Mediated Citizen Science Participation; A Motivational Model, in: Proceedings of the Fifth International Conference on Weblogs and Social Media, AAAI Press, Menlo Park, California, 2011, pp. 249-256.

[15] C. Pohl, G. Hirsch Hadorn, Principles for Designing Transdisciplinary Research, Proposed by the Swiss Academies of Arts and Science, oekom, München, 2007.

[16] G. Hirsch Hadorn, H. Hoffmann-Riem, S. Biber-Klemm, W. Grossenbacher-Mansuy, D. Joye, C. Pohl, U. Wiesmann, E. Zemp (Eds.), Handbook of Transdisciplinary Research, Springer, Dordrecht, 2008. 
[17] A. Elzinga, Participation, in: G. Hirsch Hadorn, H. Hoffmann-Riem, S. Biber-Klemm, W. Grossenbacher-Mansuy, D. Joye, C. Pohl, U. Wiesmann, E. Zemp (Eds.), Handbook of Transdisciplinary Research, Springer, Dordrecht, 2008, pp. 345-359.

[18] M. Mobjörk, Consulting versus participatory transdisciplinarity: A refined classification of transdisciplinary research, Futures 42 (2010) 866-873.

[19] W. Ulrich, Reflective Practice in the Civil Society: The Contribution of Critically Systemic Thinking, Reflective Practice 1(2) (2000) 247-268.

[20] B. Enengel, A. Muhar, M. Penker, B. Freyer, S. Drlik, F. Ritter, Co-production of knowledge in transdisciplinary doctoral theses on landscape development - An analysis of actor roles and knowledge types in different research phases, Landscape and Urban Planning 105 (2012) 106-117.

[21] M. Hage,P. Leroy, A.C. Petersen, Stakeholder participation in environmental knowledge production. Futures 42 (2010) 254-264.

[22] M. S. Reed, Stakeholder participation for environmental management: A literature review, Biological Conservation 141 (2008) 2417-2431.

[23] M. S. Reed, A. Graves, N. Dandy, H. Posthumus, K. Hubacek, J. Morris, C. Prell, C. H. Quinn, L. C. Stringer, Who's in and why? A typology of stakeholder analysis methods for natural resource management, Journal of Environmental Management 90 (2009) 1933-1949.

[24] J. Salter, J. Robinson, A. Wiek, Participatory methods of integrated assessment - a review, Wiley Interdisciplinary Reviews: Climate Change 1 (2010) 697-717.

[25] M.J. Raddick, G. Bracey, P.L. Gay, C.J. Lintott, P. Murray, K. Schawinski, A.S. Szalay, J. Vandenberg, Galaxy Zoo: Exploring the Motivations of Citizen Science Volunteers, Astronomy Education Review 9 (2010) 010103.

[26] D.C. Brabham, Moving the crowd at threadless. Motivations for participation in a crowdsourcing application. Information, Communication \& Society 13 (2010) 1122-1145.

[27] M. Hossain, Users' motivation to participate in online crowdsourcing platforms, in: Innovation Management and Technology Research (ICIMTR) 2012 International Conference on, IEEE, 2012, pp. 310-315.

[28] C. Franzoni, H. Sauermann, Crowd Science: The Organization of Scientific Research in Open Collaborative Projects, Research Policy, Forthcoming. http://dx.doi.org/10.2139/ssrn.2167538 (3.12.2013).

[29] R. Hertwig, Tapping into the Wisdom of the Crowd - with Confidence, Science 336 (2012) 303-304. 


\section{Tables}

\begin{tabular}{|c|c|c|c|}
\hline Characteristics & Crowdsourcing & Citizen Science & $\begin{array}{l}\text { Transdisciplinary } \\
\text { Research }\end{array}$ \\
\hline non-scientific projects are also realised & + & & \\
\hline scientific activities without life-worldly reference & + & + & - \\
\hline scientific activities with life-worldly reference & + & + & + \\
\hline scientific activities beyond disciplinary borders & 0 & 0 & + \\
\hline scientific projects restricted to one discipline & + & + & \\
\hline framing by general scientific guidelines & - & - & + \\
\hline hierarchical and closed scientific structures & 0 & + & 0 \\
\hline open and codetermining structures & + & - & + \\
\hline participation is open to everybody & + & + & 0 \\
\hline external experts are needed & 0 & - & 0 \\
\hline $\begin{array}{l}\text { participants are integrated to perform scientific } \\
\text { work }\end{array}$ & + & + & - \\
\hline $\begin{array}{l}\text { practice partners are integrated to consider life- } \\
\text { worldly knowledge }\end{array}$ & 0 & - & + \\
\hline $\begin{array}{l}\text { contributions are assignable and are shown } \\
\text { explicitly and promptly }\end{array}$ & + & - & 0 \\
\hline utilisation of modern web-based technologies & + & + & - \\
\hline
\end{tabular}

\section{Table1:}

Comparison of crowdsourcing, citizen science and transdisciplinary research. 


\begin{tabular}{|l|l|l|l|l}
\hline Principles & new* & add* & \multicolumn{1}{|c|}{ related roles } & \multicolumn{1}{c}{ crowdsourcing impact } \\
\hline $\begin{array}{l}\text { Participation along all research } \\
\text { phases (incl. scientific analysis) }\end{array}$ & $\boldsymbol{V}$ & & $\begin{array}{l}\text { researcher, } \\
\text { all other roles }\end{array}$ & $\begin{array}{l}\text { participation with various and flexible roles along } \\
\text { all research phases; extension of scientific tasks } \\
\text { to the community. }\end{array}$ \\
\hline Integration & $\boldsymbol{V}$ & $\begin{array}{l}\text { all roles + } \\
\text { integration of roles }\end{array}$ & $\begin{array}{l}\text { integration of contributions by cooperative } \\
\text { community activities; integration of different roles } \\
\text { and stakeholders. }\end{array}$ \\
\hline Innovation & $\boldsymbol{V}$ & $\begin{array}{l}\text { all roles + } \\
\text { variation of roles }\end{array}$ & $\begin{array}{l}\text { new innovation impulses through a variety of } \\
\text { community inputs, esp. self-organizing and } \\
\text { varying community processes. }\end{array}$ \\
\hline Recursion and Reflectivity & $\boldsymbol{V}$ & $\begin{array}{l}\text { all roles + } \\
\text { reflection of roles }\end{array}$ & $\begin{array}{l}\text { research processes, results and roles are } \\
\text { reflected by the community to find appropriate } \\
\text { revision points and new contexts. }\end{array}$ \\
\hline Validation & $\boldsymbol{v}$ & $\begin{array}{l}\text { examiners and } \\
\text { evaluators }\end{array}$ & $\begin{array}{l}\text { explicit validation phases can be organised and } \\
\text { enriched by crowdsourcing processes. }\end{array}$ \\
\hline $\begin{array}{l}\text { Mutual learning, understanding } \\
\text { and dissemination of knowledge }\end{array}$ & & $\boldsymbol{v}$ & $\begin{array}{l}\text { all roles + } \\
\text { evolution of roles }\end{array}$ & $\begin{array}{l}\text { fosters automatically transfer of research activities } \\
\text { and results by learning and role evolution within } \\
\text { the community and further dissemination. }\end{array}$ \\
\hline open management processes & $\boldsymbol{v}$ & & $\begin{array}{l}\text { all roles + } \\
\text { collegiality across roles }\end{array}$ \\
\hline
\end{tabular}

new* $^{*}$ crowdsourcing enables the application of the listed principle for transdisciplinary research add $^{*}$ : crowdsourcing strengthens the effectiveness of the transdiciplinary research principle

Table 2:

Crowdsourcing impact on transdisciplinary research and corresponding role connectivities. 